\title{
Correlation of neonatal and maternal serum magnesium levels in pre-eclamptic women
}

\begin{abstract}
Background: Pre-eclampsia carries high risk for pregnant women and their babies to develop a wide range of adverse outcomes. Unfortunately, some medications used in its management causes serious side effects if they were not monitored properly. Magnesium sulphte, being widely used in controlling and preventing convulsions in cases of severe preeclampsia, should be utilized cautiously by monitoring of its serum levels.

Objective: The aim of this study was to correlate between cord blood and maternal serum magnesium levels in pre-eclamptic women received magnesium sulphate before delivery. Patients and Methods: Cohort study on 36 pregnant women, more than 28 weeks' gestation, with the diagnosis of pre-eclampsia, who received magnesium sulphate (MgSO4), were recruited. Blood samples obtained from both maternal serum and cord blood was collected instantly at the time of delivery for detection of magnesium as well as calcium levels.

Results: $94.5 \%$ were diagnosed with pre-eclampsia, while the rest had HELLP syndrome. The treated women received total mean $\mathrm{MgSO} 4$ of $14.4 \pm 6.0$ grams during a mean duration of $5.1 \pm 3.3$ hours. Mean $\pm \mathrm{SD}$ of maternal and cord magnesium levels were $(2.2 \pm 0.4 \mathrm{mmol} / \mathrm{L})$ and $(1.8 \pm 0.3 \mathrm{mmol} / \mathrm{L})$, respectively. Significant positive correlation $(\mathrm{P}<0.001)$ between maternal magnesium and calcium levels was detected. Also, the total dose as well as the $\mathrm{MgSO} 4$ duration with maternal and cord blood magnesium levels showed significant positive correlation $(\mathrm{P}<0.001)$, but with inverse correlation with both mother's and early neonatal calcium levels. Conclusion: Magnesium and calcium detected in maternal serum and cord blood had correlated levels in pre-eclamptic women who were treated with $\mathrm{MgSO}$ therapy. As strong correlations of both magnesium and calcium between the mothers and their fetuses were demonstrated, health-care providers could use such information to give better and safer care for these patients.
\end{abstract}

Keywords: maternal blood, pre-eclampsia, calcium levels, magnesium levels, cord blood
Volume 8 Issue 3 - 2019

\author{
Ahmed Altraigey, ${ }^{1,2}$ Sara Taha Mostafaa' \\ 'Department of Obstetrics and Gynaecology, Benha University, \\ Egypt \\ ${ }^{2}$ Department of Obstetrics and Gynaecology,Armed Forces \\ Hospitals Southern Region, Saudi Arabia
}

Correspondence: Ahmed Altraigey MD, Department of Obstetrics and Gynaecology, Benha University, 43 BenhaZagazig Street, Mansheyet Elnoor, Benha, I35I I,Arab Republic of Egypt, Egypt, Tel +2010I0I37855,

Email ahmed.abdelfattah@fmed.bu.edu.eg

Received: April 24, 2017| Published: June 17, 2019

\section{Introduction}

Pre-eclampsia is diagnosed with occurrence of hypertension (moderate to severe) and significant proteinuria $(>300 \mathrm{mg} / 24 \mathrm{hour}$ urine protein collection) during pregnancy. By the incidence of about $6-8 \%$ of all pregnancies, it is considered as one of the commonly encountered serious adverse events during pregnancy. Also, it is associated with maternal and peri-natal morbidities as well as mortality. ${ }^{1-3}$ Magnesium sulphate (MgSO4) administration for prophylaxis and control of eclamptic convulsions, as an important part of the management strategy, is widely accepted despite the fact that patho-physiologic basis of their occurrence is not completely explained..$^{2-4}$

After receiving $\mathrm{MgSO} 4$, total and ionized magnesium concentration in maternal serum showed rapid rise within thirty minutes till its plateau state that achieved the required therapeutic levels of 2.0 to $3.5 \mathrm{mmol} / \mathrm{L}$. MgSO 4 acts at motor end plates reducing acetylcholine release within the neuromuscular junctions leading to direct vasodilatation. Furthermore, it is considered as a synthetic calcium antagonist. However, magnesium is largely (almost 95\%) excreted through well functioning kidneys. ${ }^{5,6}$ High magnesium levels could result in serious adverse effects in pre-eclamptic pregnant women depending on its serum levels. Minor ones included nausea, flushing and headache. Life-threatening events were associated with hypermagnesemia ( $>4.9 \mathrm{mmol} / \mathrm{L})$ such as; muscular disability, hypoventilation, ventricular arrhythmias up to cardiac arrest. Thus, health care providers should be oriented about such complications and their monitoring during $\mathrm{MgSO} 4$ administration keeping its antidote, calcium gluconate, always ready. ${ }^{6}$ Furthermore, maternal hypermagnesemia was accompanied by high neonatal serum magnesium levels through placental transfer. Moreover, antenatal maternal $\mathrm{MgSO} 4$ treatment showed transient hypermagnesemia during the early days of life of infants born to these mothers. ${ }^{7-11}$ Levels $(>2.5 \mathrm{mmol} / \mathrm{L})$ led to neonatal systemic hypotension, central nervous system (CNS) and respiratory depression. Serum magnesium (>7.4 $\mathrm{mmol} / \mathrm{L}$ ) could lead to complete heart block or asystole. Maternal high magnesium levels also affected fetal calcium metabolism, leading to neonatal hypocalcaemia due to immediate block of calcium placental transfer. If serum calcium reached levels lower than 1.6-1.7 $\mathrm{mmol} / \mathrm{L}$ in either term or preterm neonates, it would cause wide range of problems such as; neuromuscular irritability up to convulsions, respiratory arrest or arrhythmias. ${ }^{12-15}$ The primary aim of this research was to correlate meticulously between maternal and early neonatal magnesium as well as calcium levels in pre-eclamptic women given $\mathrm{MgSO} 4$ as mandatory step in their management plan.

\section{Patients and methods}

After ethical approval, this cohort study was performed between September 2014 and May 2017 at the Department of Obstetrics and Gynaecology, Armed Forces Hospitals Southern Region, Khamis 
Mushayt, Saudi Arabia. A total of 36 pregnant women, of 28 weeks' gestation or more with diagnosis of pre-eclampsia were enrolled.

\section{Diagnosis}

Based on standard criteria, pre-eclampsia was diagnosed if systolic blood pressure was recorded to be higher than $140 \mathrm{mmHg}$ or diastolic blood pressure higher than $90 \mathrm{mmHg}$, while proteinuria was defined as urinary excretion of at least $300 \mathrm{mg}$ or more in 24 -hour urine collection. Exclusion criteria were pregnancies terminated iatrogenically before 24 weeks, multiple pregnancy and renal impairment. Also, women with history of using specific drugs that altered magnesium or calcium metabolism (like corticosteroid, thyroxine or calcium channel blockers) were excluded. According our proper practice guidelines, a loading dose of $4 \mathrm{~g}$ of $\mathrm{MgSO} 4$ over 30 minutes followed by a continuous intravenous infusion of $1 \mathrm{~g}$ hourly for at least 24 hours was administered to all pregnant women diagnosed with severe preeclampsia. Initially after two hours, maternal magnesium level was followed till confirmation that it peaked to the needed therapeutic range between 2.0 and $3.5 \mathrm{mmol} / \mathrm{L}$ and subsequently at intervals based on laboratory results and the clinical situation. Dose was adjusted if needed. Complete blood count, coagulation profile and liver enzymes were also checked. MgSO4 toxicity was continuously monitored, including maternal deep tendon reflex (if disappeared), respiratory rate (less than 16/ minute) and urine output (less than $30 \mathrm{ml}$ each hour or $100 \mathrm{ml}$ every three hours). A short corticosteroid course (two $12 \mathrm{mg}$ doses of dexamethasone by intramuscular injection 12 hours interval) was administered in preterm cases (less than 34 weeks'gestation).

Vaginal delivery was the delivery route of choice. When indicated, due to pre-eclampsia or other obstetric indications pregnancy was terminated by either induction or augmentation of labour. Labour progress was monitored according to standard institutional guidelines. Caesarean delivery was conducted solely according to obstetric indications. At the time of delivery, 4 to $6 \mathrm{~mL}$ samples were collected from both maternal and umbilical cord venous blood labelled and finally stored for further processing in lithium heparin-coated tubes.

The certified laboratory at the Clinical Pathology Department of Armed Forces Hospitals Southern Region revealed the results within two hours. Colorimetric end-point was used to measure magnesium levels, while o-cresolphthalein complexone (OCPC) reaction measured calcium levels. Baseline characteristics as obstetric history, pre-eclampsia characteristics and $\mathrm{MgSO} 4$ details were recorded. Baseline characteristics, descriptive data, are represented as mean, standard deviation, number, and percentage and intergroup differences were measured by student $(\mathrm{t})$ test. Also, the correlation between magnesium and calcium levels in mothers and neonates were determined by the use of Pearson's correlation. P-value $<0.05$ was indicator for statistical significance. We used SPSS Inc., (Statistical Program for Social Science Inc.,) Chicago, IL, USA, version 21.

\section{Results}

36 pre-eclamptic pregnant women were enrolled. (89\%) suffered from pre-eclampsia, while $(5.5 \%$ each) had super-imposed pre-eclampsia or HELLP syndrome. Six (16.7\%) women only had abnormal baseline blood tests' results. They all had lactate dehydrogenase $(\mathrm{LDH})$ of more than $450 \mathrm{U} / \mathrm{L}$, two (5.5\%) had abnormal (elevation more than double the normal range) Aspartate Transaminase (AST) and serum Alanine Transaminase (ALT). Table 1 summarizes the baseline characteristics of the study groups. The range of maternal age was between 18 and 40 years. The mean gestational age at delivery ranged from 32 to 41 weeks' gestation and body mass index (BMI) mean was $27.5 \mathrm{~kg} / \mathrm{m}^{2}$. Nulliparous women formed $55.6 \%$ of study participants. Two-thirds (63.9\%) of women delivered by caesarean section and the commonest indication was the failure of induction of labour. Mean birth-weight ranged between 1350 and 4350 grams as shown in Table 2. Only two babies (5.6\%) got a low Apgar score (less than7) at 1 minute, while all had a ( \pm 7$)$ Apgar score at 5 minutes. No serious neonatal adverse events were recorded. Nevertheless, no newborns showed symptoms or signs due to unusual serum magnesium or calcium levels.

Table I Clinical data of pre-eclamptic women

\begin{tabular}{ll}
\hline Characteristic & Mean $\pm S D$ (Min-Max) or \% \\
\hline Maternal age (years) & $27.4 \pm 6.4$ \\
Gestational age (weeks) & $38.1 \pm 1.8$ \\
Body mass index (kg/m2) & $27.5 \pm 4.8$ \\
Nulliparity & $20(55.6 \%)$ \\
Pre-eclampsia & $32(89 \%)$ \\
Superimposed pre-eclampsia & $2(5.5 \%)$ \\
HELLP syndrome & $2(5.5 \%)$ \\
Normal Laboratory results & $30(83.3 \%)$ \\
Elevated LDH & $6(16.7 \%)$ \\
Elevated ALT/AST & $2(5.5 \%)$ \\
\hline
\end{tabular}

Table 2 The obstetric and neonatal outcomes of the study group

\begin{tabular}{ll}
\hline Characteristic & Mean士SD (Min-Max) \\
\hline Normal vaginal delivery & I I (30.6\%) \\
Instrumental vaginal delivery & $2(5.6 \%)$ \\
Cesarean delivery & $23(63.9 \%)$ \\
Birthweight (g) & $3103.3 \pm 6 \mid 7.4$ \\
Apgar score<7 At I min & $2(5.6)$ \\
Apgar score<7 At 5 min & $0(0)$
\end{tabular}

Table 3 shows the clinical and laboratory data related to $\mathrm{MgSO}_{4}$ administration including; dose, duration, maternal serum, cord blood magnesium and calcium levels. Women received total mean $\mathrm{MgSO}_{4}$ of $14.4 \pm 6.0$ grams before delivery and the duration of the treatment ranged from one hour to 16 hours. However, studying delivery samples revealed that 27 women $(75 \%)$ had therapeutic serum magnesium levels and no women had a toxic level. It was noticed that there were slightly lower cord blood magnesium levels, but slightly higher cord blood calcium levels were when both compared to such maternal serum levels. We initiated a correlation matrix in Table 4 to examine accordance between magnesium and calcium levels in maternal and cord venous blood and $\mathrm{MgSO}_{4}$ dose as well as duration when used intra-partum. Maternal serum magnesium $(\mathrm{P}<0.001)$ and calcium $(\mathrm{P}<0.001)$ levels had correlated significantly with their cord blood levels. Although there was an inverse correlation between maternal/ cord magnesium $(\mathrm{P}=0.436)$ levels with maternal/cord calcium $(\mathrm{P}=0.214)$ levels, it was not statistically significant. Moreover, 
magnesium levels in both maternal serum and cord blood showed significant positive correlation with $\mathrm{MgSO}_{4}$ total dose and duration. Significant negative correlation was found between total $\mathrm{MgSO}_{4}$ with calcium levels detected in maternal serum and cord blood, while $\mathrm{MgSO} 4$ duration showed the same correlation solely with maternal serum calcium.

Table $3 \mathrm{MgSO}_{4}$ dosage and duration with maternal and cord magnesium and calcium level

\begin{tabular}{ll}
\hline Characteristic & Mean \pm SD (Min-Max) \\
\hline Total MgSO4 dose $(\mathrm{g})$ & $14.4 \pm 6.0(5.5-34.5)$ \\
Administered MgSO4 duration (hours) & $5.1 \pm 3.3$ \\
Maternal magnesium level (mmol/L) & $2.2 \pm 0.4(\mathrm{I} .6-3.2)$ \\
Maternal calcium level (mmol/L) & $2.1 \pm 0.1(1.8-2.5)$ \\
Cord magnesium level (mmol/L) & $1.8 \pm 0.3(1.4-2.9)$ \\
Cord calcium level (mmol/L) & $2.4 \pm 0.1(2.2-2.9)$ \\
\hline
\end{tabular}

\section{Discussion}

Pre-eclampsia remains a life-threatening maternal health problem that leads to serious maternal and neonatal morbidity and even mortality. ${ }^{2}$ For decades, the use of $\mathrm{MgSO}_{4}$ as prophylaxis against convulsions is universally accepted to be the standard measure. ${ }^{4,6}$ The ideal therapeutic level to prevent potential seizures among pre- eclamptic women was agreed to be in the range of 2.0 to $3.5 \mathrm{mmol} / \mathrm{L}$ that offered fewer minor effects of maternal high magnesium levels. Magnesium ions are able to pass through the placenta and are taken up by different foetal tissues, levels of magnesium in the amniotic fluid, foetus and newborns of mothers received $\mathrm{MgSO}_{4}$ showed raised concentrations when compared to controls. ${ }^{16}$

Our results revealed that a strong positive correlation $(\mathrm{r}=0.95$, $\mathrm{P}<0.001)$ between maternal and cord magnesium levels that were also significantly correlated with administered $\mathrm{MgSO}_{4}$ total dose and duration. A previous veterinary research reported that tagged magnesium was actively concentrated in pregnant rabbit placenta which was instantly taken-up by the foetal tissues. ${ }^{17}$ The same mechanism thought to happen among humans also and could be responsible for the high magnesium levels detected in cord blood, ${ }^{18}$ similar to our study's findings. Magnesium freely moves across the placenta, therefore babies of mothers treated antenatally with $\mathrm{MgSO}_{4}$ might have temporary high magnesium levels during their first days of early neonatal life. ${ }^{10}$ Other articles demonstrated that neonatal serum magnesium concentrations were doubled when compared to control concentrations in mothers who were treated with $\mathrm{MgSO}_{4}$ infusions of $1-2 \mathrm{~g} / \mathrm{h}$ due to severe pre-eclampsia and the samples obtained from umbilical blood vessels showed the highest concentrations. These differences disappeared spontaneously by 48 hours after birth. ${ }^{16,19}$ Nevertheless, hypermagnesemia could be detected in fullterm neonates with adequate growth exposed to maternal $\mathrm{MgSO}_{4}$ treatment. ${ }^{16}$ Fortunately, that observation was not shown in our results.

Table 4 Correlation between maternal and cord magnesium and calcium levels as well as total $\mathrm{MgSO} 4$ dosage and duration

\begin{tabular}{|c|c|c|c|c|c|c|}
\hline & $\begin{array}{l}\text { Maternal Mg } \\
(\mathrm{mmol} / \mathrm{L})\end{array}$ & Cord Mg & $\begin{array}{l}\text { Maternal calcium } \\
(\mathrm{mmol} / \mathrm{L})\end{array}$ & $\begin{array}{l}\text { Cord calcium } \\
(\mathrm{mmol} / \mathrm{L})\end{array}$ & $\begin{array}{l}\text { Total } \\
\text { MgSO4 (g) }\end{array}$ & $\begin{array}{l}\text { MgSO4 duration } \\
\text { (hours) }\end{array}$ \\
\hline & & (mmol/L) & & & & \\
\hline \multirow[t]{2}{*}{$\begin{array}{l}\text { Maternal Mg } \\
(\mathrm{mmol} / \mathrm{L})\end{array}$} & - & $P<0.001$ & $P=0.436$ & $P=0.297$ & $P<0.001$ & $P=0.002$ \\
\hline & & 0.95 & -0.13 & -0.18 & 0.6 & 0.49 \\
\hline \multirow[t]{2}{*}{ Cord $\mathrm{Mg}(\mathrm{mmol} / \mathrm{L})$} & $P<0.001$ & - & $P=0.299$ & $P=0.24 I$ & $P<0.001$ & $P=0.001$ \\
\hline & 0.95 & & -0.18 & -0.21 & 0.65 & 0.52 \\
\hline \multirow[t]{2}{*}{$\begin{array}{l}\text { Maternal calcium } \\
(\mathrm{mmol} / \mathrm{L})\end{array}$} & $P=0.436$ & $P=0.299$ & - & $P<0.001$ & $P=0.014$ & $P=0.027$ \\
\hline & -0.13 & -0.18 & & 0.75 & 0.4 & -0.37 \\
\hline \multirow[t]{2}{*}{$\begin{array}{l}\text { Cord calcium } \\
\text { (mmol/L) }\end{array}$} & $P=0.297$ & $P=0.214$ & $P<0.001$ & - & $P=0.026$ & $P=0.059$ \\
\hline & -0.18 & -0.21 & 0.75 & & -0.37 & -0.32 \\
\hline \multirow[t]{2}{*}{ Total $\mathrm{MgSO}_{4}(\mathrm{~g})$} & $P<0.001$ & $P<0.001$ & $P=0.014$ & $P=0.026$ & - & $P<0.001$ \\
\hline & 0.6 & 0.65 & -0.4 & -0.37 & & 0.88 \\
\hline \multirow[t]{2}{*}{$\begin{array}{l}\mathrm{MgSO}_{4} \text { duration } \\
\text { (hours) }\end{array}$} & $P=0.002$ & $P=0.001$ & $P=0.027$ & $P=0.059$ & $P<0.001$ & - \\
\hline & 0.49 & 0.52 & -0.37 & -0.32 & 0.88 & \\
\hline
\end{tabular}


Magnesium can compete with calcium metabolism. ${ }^{15}$ High magnesium levels affected the parathyroid hormone, and hence calcium levels. ${ }^{10,19}$ when high dose of $\mathrm{MgSO}_{4}$ prescribed to preeclamptic women, they could reduce placental calcium transfer, as a protective mechanism by the placenta. ${ }^{14}$ Low maternal calcium levels noticed in the present work could be due to a synergistic effect of the disease process itself as well as the high extracellular magnesium concentrations. ${ }^{19,20}$ Also, this affects neonatal calcium metabolism; as a significant $(\mathrm{P}<0.01)$ correlation between calcium levels withdrawn from maternal and cord samples was observed. Prolonged $\mathrm{MgSO}_{4}$ administration, for tocolysis and preterm birth prevention showed significantly lower calcium levels in newborns. ${ }^{15}$ In contrary, a previous article revealed that calcium levels withdrawn from umbilical cord blood were comparable between $\mathrm{MgSO}_{4}$ treated pre-eclamptic mothers and controls. The maternal magnesium levels at delivery were not correlated with calcium levels obtained from either umbilical cord or neonatal blood. ${ }^{19}$ Our study faced some limitations. First, total magnesium and calcium concentration varied based on multiple parameters including; glomerular filtration, body mass index, protein and haemoglobin values. Additionally, we were not able to evaluate the ionized levels of studied elements which are the most significant representative of the bioactive portion. Aali et al., ${ }^{5}$ revealed absence of accordance between both forms magnesium (total and ionized) in pre-eclamptic women and concluded that total magnesium detection was not adequate for the therapeutic $\mathrm{MgSO}_{4}$ infusion titration. ${ }^{5}$ Moreover, investigating the superiority of ionized magnesium for pre-eclampsia surveillance among women receiving $\mathrm{MgSO}_{4}$ needs further studies.

\section{Conclusion}

Our results could add some information regarding magnesium and calcium kinetics in maternal and neonatal circulation of pre-eclamptic women treated with $\mathrm{MgSO}_{4}$ therapy. There was positive correlation between magnesium and calcium levels of maternal and early neonatal samples, but they were inversely correlated with calcium levels. Also, $\mathrm{MgSO}_{4}$ dose and duration affected both levels. These findings could be beneficial if utilized to conduct proper practice guidelines for closer and prudent follow up of pregnant ladies and their babies. All health care professionals should be aware and alert for potential early neonatal high magnesium levels or low calcium levels when observing babies of pre-eclamptic mothers having $\mathrm{MgSO}_{4}$ therapy, particularly for long duration.

\section{Acknowledgments}

None.

\section{Conflicts of interest}

The author declares there are no conflicts of interest.

\section{References}

1. Report of the National High Blood Pressure Education Program Working Group on high blood pressure in pregnancy. Am J Obstet Gynecol. 2000;183(1):S1-S22.

2. Duley L. The global impact of pre-eclampsia and eclampsia. Semin Perinatol. 2009;33(3):130-137.
3. Sibai BM. Magnesium sulfate prophylaxis in preeclampsia. Evidence from randomized trials. Clin Obstet Gynecol. 2005;48(2):478-488.

4. Norwitz ER, Repke JT. Preeclampsia prevention and management. J Soc Gynecol Investig. 2000; 7(1):21-36.

5. Aali BS, Khazaeli P, Ghasemi F. Ionized and total magnesium concentration in patients with severe preeclampsia-eclampsia undergoing magnesium sulfate therapy. J Obstet Gynaecol Res. 2007;33(2):138-143.

6. Cunnigham FG, Leveno KJ, Blomm SL, et al. Williams Obstetrics. 22nd edition. New York: McGraw-Hill; 2005. p.761-800.

7. Harker HE, Majcher TA. Hypermagnesemia in a pediatricpatient. Anesth Analg. 2000;91(5):1160-1162.

8. Deshpande GG, Gharpure V, Sarnaik AP, et al. Acute hypermagnesemia in a child. Am J Health Syst Pharm. 2006 63(3):262-265.

9. Schanler RJ, Smith LG Jr, Burns PA. Effects of long-term maternal intravenous magnesium sulfate therapy on neonatal calcium metabolism and bone mineral content. Gynecol Obstet Invest. 1997;43(4):236-241.

10. Rantonen T, Kaapa P, Jalonen J, et al. Antenatal magnesium sulphate exposure is associated with prolonged parathyroidhormone suppression in preterm neonates. Acta Paediatr. 2001;90(3):278-281.

11. Mason BA, Standley CA, Whitty JE, et al. Fetal ionized magnesium levels parallel maternal levels during magnesium sulfate therapy for preeclampsia. Am J Obstet Gynecol. 1996;175(1): 213-217.

12. Rigo J, De Curtis M. Disorders of Calcium, Phosphorus and Magnesium Metabolism: Diseases of the Fetus and Infant. 8th edition. Philadelphia, PA: Mosby Elsevier; 2006. 1493 p.

13. Broner CW, Stidham GL, Westenkirchner DF. Hypermagnesemia and hypocalcemia as predictors of high mortality in critically ill pediatric patients. Crit Care Med. 1990;18(9):921-928.

14. Yokoyama K, Takahashi N, Yada Y, et al. Prolonged maternal magnesium administration and bone metabolism in neonates. Early Hum Dev. 2010;86(3):187-191.

15. Cruikshank DP, Pitkin RM, Reynolds WA, et al. Effects of magnesium sulfate treatment on perinatal calcium metabolism. I. Maternal and fetal responses. Am J Obstet Gynecol. 1979;134(3):243-249.

16. Lu JF, Nightingale $\mathrm{CH}$. Magnesium sulfate in eclampsia andpre-eclampsia: Pharmacokinetic principles. Clin Pharmacokinet. 2000;38(4):305-314.

17. Aikawa JK, Bruns PD. Placental transfer and fetal tissue uptake of $\mathrm{Mg} 2+$ in the rabbit. Proc Soc Exp Biol Med. 1960;105:957-959.

18. Boriboonhirunsarn D, Lertbunnaphong T, Suwanwanich M. Correlation of magnesium levels in cord blood and maternal serum among preeclamptic pregnant women treated with magnesium sulphate. $J$ Obstet Gynaecol Res. 2012;38(1):247-252.

19. McGuinness GA,Weinstein MM, Cruikshank DP, et al. Effect of magnesium sulfate treatment on perinatal calcium metabolism. II: Neonatal responses. Obstet Gynecol. 1980;56(5):595-600.

20. Cholst IN, Steinberg SF, Tropper PJ, et al. The influence of hypermagnesemia on serum calcium and parathyroid hormone levels in human subject. N Engl J Med. 1984;310(19):1221-1225. 